\title{
Retrospective analysis of clinical pathway in management of laparoscopic cholecystectomy in a tertiary care centre in south India
}

\section{Parimuthukumar Rajappa, Saravanan Sanniyasi, Prashanth Krishna Gopalaswamy*, ManuneethimaranThiyagarajan}

Department of General Surgery, Sri Ramachandra University, Chennai, Tamil Nadu, India

Received: 29 May 2016

Accepted: 17 June 2016

\section{*Correspondence:}

Dr. Prashanth Krishna,

E-mail: gp.krishna13@gmail.com

Copyright: $($ ) the author(s), publisher and licensee Medip Academy. This is an open-access article distributed under the terms of the Creative Commons Attribution Non-Commercial License, which permits unrestricted non-commercial use, distribution, and reproduction in any medium, provided the original work is properly cited.

\begin{abstract}
Background: With the advent of laparoscopy, laparoscopic cholecystectomy has become one of the most commonly performed surgeries today. In many parts of the world laparoscopic cholecystectomy is performed as a day-care procedure. The aim was to compare the efficacy of clinical pathway versus no pathway in the management of laparoscopic cholecystectomy in terms of prolonged antibiotic usage and extended hospital stay.

Methods: A study was conducted on all the patients included in the clinical pathway. The results were compared between the patients undergoing surgery the year prior and one year after the implementation of clinical pathway.

Results: It is seen that, one year prior to the implementation of the pathway, the doses of antibiotics given were about 9-10 doses and the stay in the hospital was about 4-5 days and one year following implementation of the pathway it has been noticed that the number of doses of antibiotics has reduced and is about 4-5 doses and the stay in the hospital has shortened and is about 2-3 days.

Conclusions: This study shows us the importance of having guidelines in the form of a clinical pathway for surgical procedures as it helps to streamline patient care without any compromise in the quality of care.
\end{abstract}

Keywords: Clinical pathway, Cholecystectomy, Antibiotic usage, Hospital stay

\section{INTRODUCTION}

Cholelithiasis represents one of the most common surgical problems worldwide and is especially prevalent in most western countries. In the U.S alone, gallstones are present in $10-15 \%$ of the adult population and are more likely to develop in women than in men. ${ }^{1}$ In all cultures, the incidence increases with increase in age. It is the most common indication for cholecystectomy.

With the advent of laparoscopic surgeries, laparoscopic cholecystectomy has become one of the most commonly performed surgeries today. In many parts of the world it is a day care procedure.
As a surgeon it is important to take part in the development of clinical pathways and guidelines. ${ }^{2}$ In 1998, the Southwestern surgical congress published the importance of pathways in view of reducing length of stay in the hospital and reducing the expenses for diagnosis. The guidelines, the motivation, the pros and cons of clinical pathways were analysed by these surgical congresses. ${ }^{3}$ In critical care patients, the implementation of such clinical pathways has improved the hospital care processes with the help of good collaboration of healthcare personnel without any increase in the readmission rate. ${ }^{4}$ There is a significant improvement in the duration of stay, rate of complications, and also financial outcomes in cancer patients by using such guidelines and clinical pathways. 
The implementation of clinical pathway in general surgery patients has made a promising improvement in patient care and patient satisfaction. Even though there are many pathways used in clinical practice, the application of a pathway for a single condition is rare. Since laparoscopic cholecystectomy is one of the most common procedures in our hospital, the pathway was applied for this procedure in our hospital. The aim was to compare the efficacy of the clinical pathway in laparoscopic cholecystectomy in terms of prolonged antibiotic usage and extended hospital stay.

\section{METHODS}

This was a retrospective study conducted in Sri Ramachandra University, Tamil Nadu, India, patients from 2012-2015. All laparoscopic cholecystectomy patient details were collected from 2012-2013. There was no clinical pathway applied for laparoscopic cholecystectomy patients in this period. From 2013-2015 all laparoscopic cholecystectomy patients were treated with an indigenously developed clinical pathway. The exclusion criteria are mentioned in Table 1. After excluding these patients only laparoscopically completed patients in this time period were selected for the study. Comparison between the pathway and non-pathway groups was done. Antibiotic usage and hospital stay was compared between these two groups.

Table 1: Clinical pathway for management of cholelithiasis.

\begin{tabular}{|ll|}
\hline \multirow{2}{*}{$\begin{array}{l}\text { Patients to include } \\
\text { on pathway }\end{array}$} & $\begin{array}{l}\text { Symptomatic gall stones with } \\
\text { normal LFT }\end{array}$ \\
& $\begin{array}{l}\text { Gallstones - previous } \\
\text { Cholangitis/pancreatitis }\end{array}$ \\
\hline GB polyps \\
\hline \multirow{2}{*}{$\begin{array}{l}\text { Patients to exclude } \\
\text { from pathway }\end{array}$} & $\begin{array}{l}\text { Complications like acute } \\
\text { pancreatitis }\end{array}$ \\
\cline { 2 - 2 } & Abscess, CBD stones, empyema \\
\hline & GB malignancies \\
\cline { 2 - 2 } $\begin{array}{l}\text { Conversion to open } \\
\text { Remove the patient } \\
\text { from the pathway if } \\
\text { the following } \\
\text { occurs }\end{array}$ & $\begin{array}{l}\text { Significant post-operative } \\
\text { complication such as } \\
\text { obstruction or }\end{array}$ \\
\hline $\begin{array}{l}\text { Requiring a second operation or } \\
\text { prolonged TPN }\end{array}$ \\
\hline $\begin{array}{l}\text { Transfer to a higher level of } \\
\text { care }\end{array}$ \\
\hline
\end{tabular}

Antibiotic usage was calculated based on the number of doses given to a patient. The duration of hospital stay was calculated in hours for every patient based on time of admission and time of discharge in the electronic record.

The collected data was compared between both groups of patients.

\section{Details of clinical pathway for laparoscopic cholecystectomy}

Once the patient is diagnosed with cholelithiasis, pathway will be initiated. According to the pathway, patient will be evaluated and treatment will be started. The inclusion and exclusion criteria are mentioned in Table 1. The proforma is depicted in Appendix 1. Patients undergo laparoscopic cholecystectomy in the standard technique. Those who require conversion were excluded from the study. Pathway was recorded from August 2013-July 2015.

\section{RESULTS}

A total of 502 cases have been included in this study with 260 in the non-pathway group and 242 in the pathway group. Clinical pathway was introduced in August 2013. The cases included in the non-pathway group were taken from August 2012-July 2013 and the cases included in the pathway group were from August 2014-July 2015. On comparing the age of the patients, the mean age in the non-pathway group and pathway group are almost equal $(49.12 \pm 15.67)$ and $(48.88 \pm 15.22)$. The male: female ratio of cholelithiasis patient is 1:9.5. It was noticed that prior to the introduction of the pathway the number of doses of antibiotics on an average was 9.54 and the number of days in hospital was about 4.76. After implementation of the pathway it was seen that the number of antibiotic doses had reduced to about 3.57 and the number of days in the hospital was about 2.5 days both of which were statistically significant with a $\mathrm{p}$ value of $<0.001$. These values are summarized in Table 2 .

Table 2: Effect of clinical pathway on number of doses of antibiotics and hospital stay.

\begin{tabular}{|llll|}
\hline & $\begin{array}{l}\text { Non- } \\
\text { pathway } \\
\text { group }\end{array}$ & $\begin{array}{l}\text { Pathway } \\
\text { group }\end{array}$ & $\begin{array}{l}\text { p- } \\
\text { value }\end{array}$ \\
\hline $\begin{array}{l}\text { Number of doses of } \\
\text { antibiotics }\end{array}$ & 9.54 & 3.57 & $<0.001$ \\
\hline Hospital stay (in days) & 4.76 & 2.50 & $<0.001$ \\
\hline
\end{tabular}

\section{DISCUSSION}

Laparoscopic cholecystectomy has become the standard of care in symptomatic cholelithiasis. However there is a marked variability in the diagnosis and treatment protocols across consultants. Clinical pathways have been introduced to bridge these gaps and provide improvement in clinical care in surgery. ${ }^{6}$ Pathways facilitate better team work and are very useful in health organizations. ${ }^{7}$ As part of our quality improvement, pathway for laparoscopic cholecystectomy was introduced in our hospital in August 2013. One of the major advantages we were able to derive was the reduced hospital stay which was on an average 2.26 days lesser after the introduction of the 
pathway and it was statistically significant with a p-value of $<0.001$. Soria $V$ et al and Zhang $M$ et al have also brought out this significant advantage in their study., The other major advantage brought out by our study was lesser antibiotic usage which was on an average 6 doses lesser (p-value $<0.001$ ). Dong LI et al also have recorded similar findings in their study. ${ }^{10}$ The other major advantage in their study is the decreased hospital charges. Hence, clinical pathways are a means for auditing surgical care and instituting necessary modifications for better patient outcome.

\section{CONCLUSION}

The results of the evaluation study show that a standardized clinical pathway for laparoscopic cholecystectomy is very useful to reduce the duration of hospital stay as well as the number of doses of antibiotics without any increase in complication rate and readmission rate.

\section{ACKNOWLEDGEMENTS}

Author would like to thank the chief operating officer, Medical Director and the Head of Department of General Surgery for allowing them to conduct this research.

Funding: No funding sources Conflict of interest: None declared

Ethical approval: The study was approved by the institutional ethics committee

\section{REFERENCES}

1. Stinton LM, Shaffer EA. Epidemiology of gall bladder disease: cholelithiasis and cancer. Gut Liver. 2012;6(2):172-87.
2. Gadacz TR, Adkins RB, O'Leary JP. General surgical clinical pathways: an introduction. Am Surg. 1997;63:107-10.

3. Weiland DE. Why use clinical pathways rather than practice guidelines? Am J Surg. 1997;174(6):592-5.

4. Cheah J. Clinical pathways: an evaluation of its impact on the quality of care in an acute care general hospital in Singapore. Singapore Med J. 2000;41:335-46.

5. Smith TJ, Hillner BE. Ensuring quality cancer care by the use of clinical practice guidelines and critical pathways. J Clin Oncol. 2001;19(11):2886-97.

6. Ronellenfitsch U, Rossner E, Jakob J, Post S, Hohenberger P, Schwarzbach M. Clinical pathways in surgery: should we introduce them into clinical routine? A review article. Langenbecks Arch Surg. 2008;393(4):449-57.

7. Deneckere S, Euwema M, Van HP, Lodewijckx C, Panella M, Sermeus W, Vanhaecht K. Care pathways lead to better teamwork: results of a systematic review. Soc Sci Med. 2012;75(2):264-8.

8. Soria V, Pellicer E, Flores B, Carrasco M, Candel MF, Aguayo JL. Evaluation of the clinical pathway for laparoscopic cholecystectomy. Am Surg. 2005;71(1):40-5.

9. Zhang M, Zhou SY, Xing MY, Xu J, Shi XX, Zheng SS. The application of clinical pathways in laparoscopic cholecystectomy. Hepatobiliary Pancreat Dis Int. 2014;13(4):348-53.

10. Dong C, Shen H, Wang Y, Ming MUQ, Huang LS, Rong HU. Application of clinical pathways in laparoscopic cholecystectomy: a contemporary, case-matched, clinical controlled study. Chinese J Evidence Based Med. 2014;14(2):156-61.

Cite this article as: Rajappa $\mathrm{P}$, Sanniyasi S, Gopalaswamy PK, Thiyagarajan M. Retrospective analysis of clinical pathway in management of laparoscopic cholecystectomy in a tertiary care centre in south India. Int Surg J 2016;3:1163-6. 
Appendix 1: Proforma.

Clinical pathway: LAP cholecystectomy

(A - Adherent, D - Deviation, E - Exclusion)

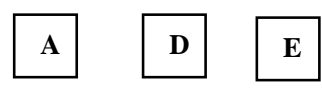

Patient Name:

Age:

Sex: M/F

DOA: $>48 \mathrm{hrs}$ post op stay: YES/NO

Primary Surgeon:

Hospital No:

Diagnosis: Calculous/Acalculouscholecystitis

DOD:

USG Abd:

ASA - I/II/III/IV/V

Procedure done: Lap cholecystectomy alone / combined with

Drain kept: Yes/No. If yes, (Reason)

Antibiotic used \& dose (only 3 doses)

$$
\begin{aligned}
& \text { (>3; Reason) } \\
& (>3 \text {;Reason })
\end{aligned}
$$

Complications if any:

Re exploration

YES/NO

Injury to adjacent organ/CBD

YES/NO

Blood loss/bleeding

Post op bile leak

YES/NO

Undue post op pain \& Vomiting

YES/NO 